\title{
Model Predictive Direct Power Control of DC Micro Grid Rectifier Based on Neutral Point Potential Balance
}

\author{
Lu Xiaojuan, Wang Xinju, and Dong Haiying \\ School of Automation and Electrical Engineering, Lanzhou Jiaotong University, Lanzhou, Gansu 730070, China \\ Correspondence should be addressed to Lu Xiaojuan; luxj@mail.lzjtu.cn
}

Received 11 November 2016; Accepted 15 May 2017; Published 1 June 2017

Academic Editor: Antonios Tsourdos

Copyright (C) $2017 \mathrm{Lu}$ Xiaojuan et al. This is an open access article distributed under the Creative Commons Attribution License, which permits unrestricted use, distribution, and reproduction in any medium, provided the original work is properly cited.

\begin{abstract}
Aimed at the problem of DC micro grid rectifier control delay and the DC bus voltage stability, the method of two-step model predictive direct power control (TMPDPC) combined with neutral point potential control is proposed. Model predictive direct power control (MPDPC) is designed for rectifier. A cost function is then used to evaluate the active and reactive power ripples, from which the vector that generates the lowest power ripple will be applied during the next sampling interval. Two-step predictive control is designed to compensate for the delay of one-step predictive control. On the basis of this, the two-capacitor voltage unbalance problem in DC side is considered, and the neutral point potential control is added. In the Matlab/Simulink simulation, compared with control effect of direct power control (DPC) and one-step model predictive direct power control (OMPDPC), the control strategy of neutral point potential added to TMPDPC can make the system stability and control accuracy better. The validity of this scheme was validated by physical simulation at last.
\end{abstract}

\section{Introduction}

DC micro grid as a kind of micro network which can connect the distributed power and main network has more flexible reconfiguration capability compared with the AC micro grid [1]. For solar thermal power generation, wind power generation, and turbine power generation, the electricity produced by generator supplies the DC bus after AC/DC transformation, and the control performance of the rectifier directly affects the stable operation of the DC micro grid. Therefore, there are many control methods of rectifier in the distributed energy and micro grids are concerned by more and more people. At present, the high performance control method of PWM rectifier mainly includes voltage oriental control (VOC), which can obtain good dynamic performance and steady state performance, but it is strongly dependent on the proportional integral (PI) parameter. DPC has the advantages of simple algorithm and fast dynamic response without coordinate rotation transformation, but its steady state ripple is relatively large [2,3]. In recent years, the application of model predictive control (MPC) is also concerned. MPC uses the dynamic model of the system to predict the current/power of the next moment. Compared to
DPC, MPC is more accurate and effective in vector selection, of which the principle is simple and easy to implement, and it has good dynamic and static performance [4-12]. But one-step prediction is most used currently. In order to solve the problem of delay in the control of the rectifier, the literature [13] uses two-step model predictive direct power control (TMPDPC), which achieves very good results. DC side capacitor voltage balancing problems are not included in the above literature, and in this paper, based on the SVPWM modulation method, a method is introduced to control the balance of neutral point potential by the method of detecting the negative small vector corresponding to the balance current to assist the regulation of the positive and negative small vectors $[14,15]$. Based on the above analysis, this paper designed two-step predictive power control combined with neutral point potential method to realize the stability of DC power supply. The main research work includes the following:

(1) OMPDPC is applied to solve the problem that the frequency of the switch of look-up table direct power control (UT-DPC) is not constant. OMPDPC can obtain good steady state and dynamic response and is convenient for the design of power filter. 


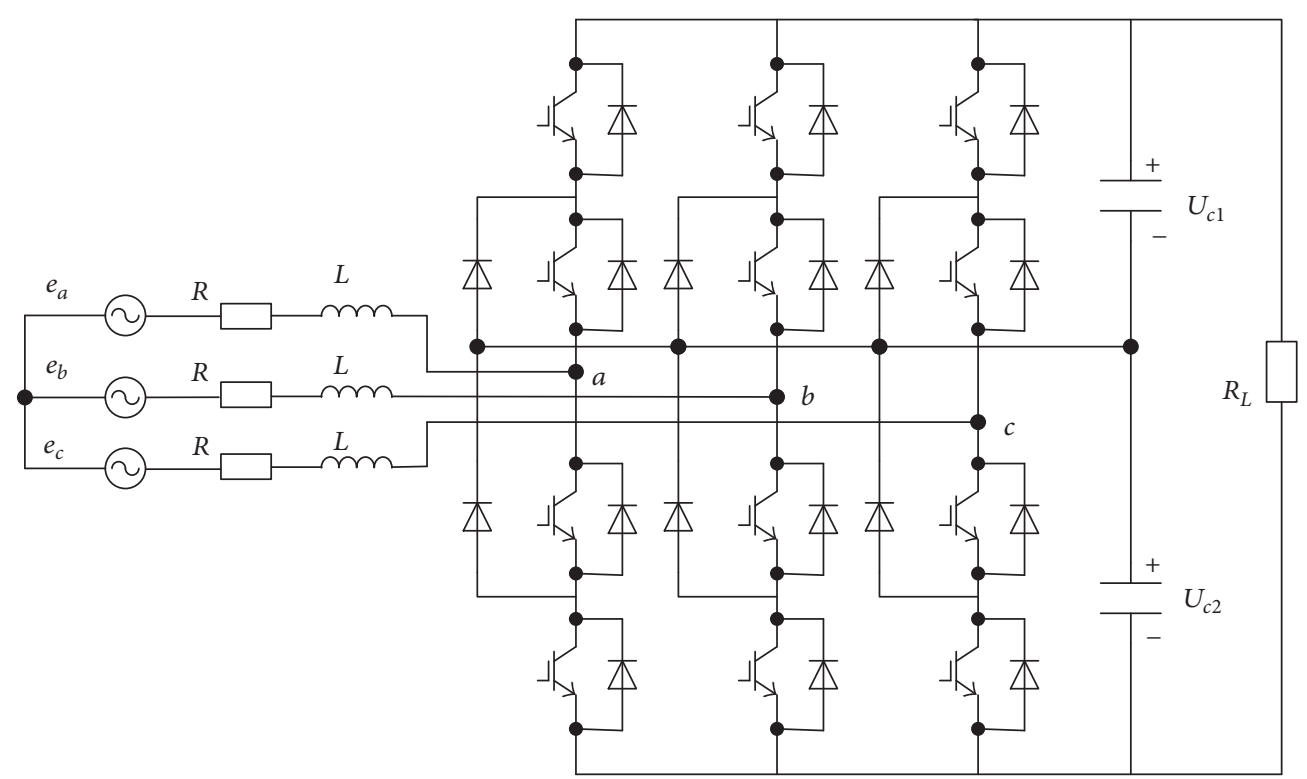

FIGURE 1: Topology of DC micro grid rectifier using diode block three-level pulse rectifier.

(2) TMPDPC method is used to solve the delay problem in OMPDPC process.

(3) Aiming at the problem of unbalanced voltage of two capacitors in DC side, based on TMPDPC and SVPWM modulation, the balance of the neutral point potential is realized by adjusting the action time of the positive and negative small vectors to eliminate the voltage fluctuation of the neutral point potential.

Three control algorithms are compared and analyzed, and the control method of TMPDPC combined with neutral point potential control is the best. The application of this method has practical engineering application value.

\section{Rectifier Model Structure}

The topology of DC micro grid rectifier using diode block three-level pulse rectifier is shown in Figure 1 , where $e_{a}, e_{b}$, $e_{c}$ are network side voltage, $R, L$ are network side resistance and inductance, $C_{1}, C_{2}$ are DC side capacitors, and $R_{L}$ is load side equivalent resistance.

In the three-phase power network voltage balance, according to Kirchhoff's law, the dynamic equation in the static coordinates is as follows:

$$
V_{\alpha \beta}=e_{\alpha \beta}-L \frac{d I_{\alpha \beta}}{d t}-R I_{\alpha \beta},
$$

where $e_{\alpha \beta}, V_{\alpha \beta}$ are, respectively, the supply voltage and the input voltage of the rectifier in the two-phase stationary coordinate system and $I_{\alpha \beta}$ is the line current. According to the instantaneous power theory, the instantaneous active and reactive power of the AC side of the system can be expressed as follows:

$$
\left(\begin{array}{l}
P \\
Q
\end{array}\right)=\frac{3}{2}\left(\begin{array}{cc}
e_{\alpha} & e_{\beta} \\
e_{\beta} & -e_{\alpha}
\end{array}\right)\left(\begin{array}{c}
I_{\alpha} \\
I_{\beta}
\end{array}\right)
$$

\section{Model Predictive Direct Power Control (MPDPC)}

3.1. Principle of $M P D P C$. After active power and reactive power derivation, the instantaneous power change rate is as follows:

$$
\begin{aligned}
\left(\begin{array}{c}
\frac{d P}{d t} \\
\frac{d Q}{d t}
\end{array}\right)= & \frac{3}{2}\left(\begin{array}{cc}
\frac{d e_{\alpha}}{d t} & \frac{d e_{\beta}}{d t} \\
\frac{d e_{\beta}}{d t} & -\frac{d e_{\alpha}}{d t}
\end{array}\right)\left(\begin{array}{c}
I_{\alpha} \\
I_{\beta}
\end{array}\right) \\
& +\frac{3}{2}\left(\begin{array}{cc}
e_{\alpha} & e_{\beta} \\
e_{\beta} & -e_{\alpha}
\end{array}\right)\left(\begin{array}{c}
\frac{d I_{\alpha}}{d t} \\
\frac{d I_{\beta}}{d t}
\end{array}\right) .
\end{aligned}
$$

Under ideal grid voltage condition, the instantaneous voltage change rate is

$$
\left(\begin{array}{c}
\frac{d e_{\alpha}}{d t} \\
\frac{d e_{\beta}}{d t}
\end{array}\right)=\left(\begin{array}{cc}
0 & -\omega \\
\omega & 0
\end{array}\right)\left(\begin{array}{l}
e_{\alpha} \\
e_{\beta}
\end{array}\right) .
$$

Combining formula (2) and formula (3), instantaneous current change rate is

$$
\begin{aligned}
\left(\begin{array}{c}
\frac{d I_{\alpha}}{d t} \\
\frac{d I_{\beta}}{d t}
\end{array}\right)= & \left(\begin{array}{cccc}
-\frac{R}{L} & 0 & -\frac{1}{L} & 0 \\
0 & -\frac{R}{L} & 0 & -\frac{1}{L}
\end{array}\right)\left(\begin{array}{c}
I_{\alpha} \\
I_{\beta} \\
e_{\alpha} \\
e_{\beta}
\end{array}\right) \\
& +\left(\begin{array}{cc}
\frac{1}{L} & 0 \\
0 & \frac{1}{L}
\end{array}\right)\left(\begin{array}{c}
V_{\alpha} \\
V_{\beta}
\end{array}\right) .
\end{aligned}
$$


Formula (3) is brought into formula (4); then

$$
\begin{aligned}
\left(\begin{array}{c}
\frac{d P}{d t} \\
\frac{d Q}{d t}
\end{array}\right)= & \left(\begin{array}{rr}
-\frac{R}{L} & -\omega \\
\omega & -\frac{R}{L}
\end{array}\right)\left(\begin{array}{l}
P \\
Q
\end{array}\right) \\
& +\frac{3}{2 L}\left(\begin{array}{cc}
e_{\alpha} & e_{\beta} \\
e_{\beta} & -e_{\alpha}
\end{array}\right)\left(\begin{array}{l}
V_{\alpha} \\
V_{\beta}
\end{array}\right) \\
& -\frac{3}{2 L}\left(\begin{array}{ll}
e_{\alpha} & e_{\beta}
\end{array}\right)\left(\begin{array}{l}
e_{\alpha} \\
e_{\beta}
\end{array}\right) .
\end{aligned}
$$

Let

$$
\begin{aligned}
y(k) & =\left(\begin{array}{l}
P(k) \\
Q(k)
\end{array}\right), \\
A & =\left(\begin{array}{rr}
-\frac{R}{L} & -\omega \\
\omega & -\frac{R}{L}
\end{array}\right), \\
B & =\left(\begin{array}{cc}
e_{\alpha} & e_{\beta} \\
e_{\beta} & -e_{\alpha}
\end{array}\right), \\
C & =\left(\begin{array}{cc}
e_{\alpha} & e_{\beta} \\
0 & 0
\end{array}\right),
\end{aligned}
$$

and the above formula can be simplified as

$$
\frac{d y}{d t}=A y+\frac{3}{2 L} B V-\frac{3}{2 L} C e .
$$

Formula (8) is discretized to obtain the model prediction equation as shown in

$$
\begin{aligned}
y(k+1)= & y(k) \\
& +T_{s}\left[A y(k)+\frac{3}{2 L} B V(k)-\frac{3}{2 L} C e(k)\right] .
\end{aligned}
$$

In order to obtain more accurate system response, before the start of a switching cycle, the reference value of each phase of the PWM should be set. Considering the reference voltage of the rectifier in one switching cycle whose value remains unchanged, a periodic point voltage can be used as an approximation, and neutral point voltage $e(k+1 / 2)$ can be obtained through $e(k-2), e(k-1)$, and $e(k)$ estimation. This paper uses Newton interpolation to predict the midpoint voltage which is simple and easy to calculate $[16,17]$. The obtained midpoint position voltage value is

$$
\begin{aligned}
e\left(k+\frac{1}{2}\right)= & 1.875 e(k)-1.25 e(k-1) \\
& +0.375 e(k-2)
\end{aligned}
$$

Then the system prediction model is changed into

$$
\begin{aligned}
y(k+1) & \\
= & y(k) \\
& +T_{s}\left[A y(k)+\frac{3}{2 L} B V(k)-\frac{3}{2 L} C e\left(k+\frac{1}{2}\right)\right] .
\end{aligned}
$$

Aimed at the tracking control problem of the output of the system, the optimization performance index of the system is designed as follows:

$$
J=\left(P^{*}-P(k+1)\right)^{2}+\left(Q^{*}-Q(k+1)\right)^{2} .
$$

Figure 2 is the block diagram of direct power control for three-level pulse rectifier model, where the PWM modulation unit adopts the SVPWM modulation method.

3.2. One-Step Predictive Control Delay Compensation. In practical systems, the sampling and algorithm of the system cannot be completed instantaneously, and there is a cycle of control delay; that is to say, the voltage vector in the $k$ cycle is used in the $k+1$ cycle. In this paper, the two-step prediction method is used to eliminate the delay; that is, formula (11) can be used to predict $P(k+1)$ and $Q(k+1)$. Assume that the supply voltage within a sampling period remains constant, set $P(k+1)$ and $Q(k+1)$ as the new initial state variables, and then $V_{i}(k)$ as the input can predict $P(k+2)$ and $Q(k+2)$.

By formula (6), we will get

$$
y(k+2)=\left(\begin{array}{l}
P(k+2) \\
Q(k+2)
\end{array}\right) .
$$

According to the predictive model that is shown in formula (11) in this paper, through two-step prediction, we will get

$$
\begin{aligned}
& y(k+2)=y(k+1)+T_{s}[A y(k+1) \\
& \left.+\frac{3}{2 L} B V(k+1)-\frac{3}{2 L} C e\left(k+1+\frac{1}{2}\right)\right] .
\end{aligned}
$$

At this time, the system optimization performance index can be designed as

$$
J=\left(P^{*}-P(k+2)\right)^{2}+\left(Q^{*}-Q(k+2)\right)^{2} .
$$

3.3. Neutral Point Potential Control. The neutral point voltage unbalance directly affects the performance of the rectifier, which influences the power quality of the power grid, increases the pressure of the power switch, and reduces the reliability of the system. When the SVPWM modulation is used, the balance of the neutral point potential is controlled by the method of detecting the balance current of the negative small vector to adjust the action time of the positive and negative small vectors to control the neutral point potential [18]. The corresponding relationship between each small vector and midpoint current $i_{n}$ is shown in Table 1. 


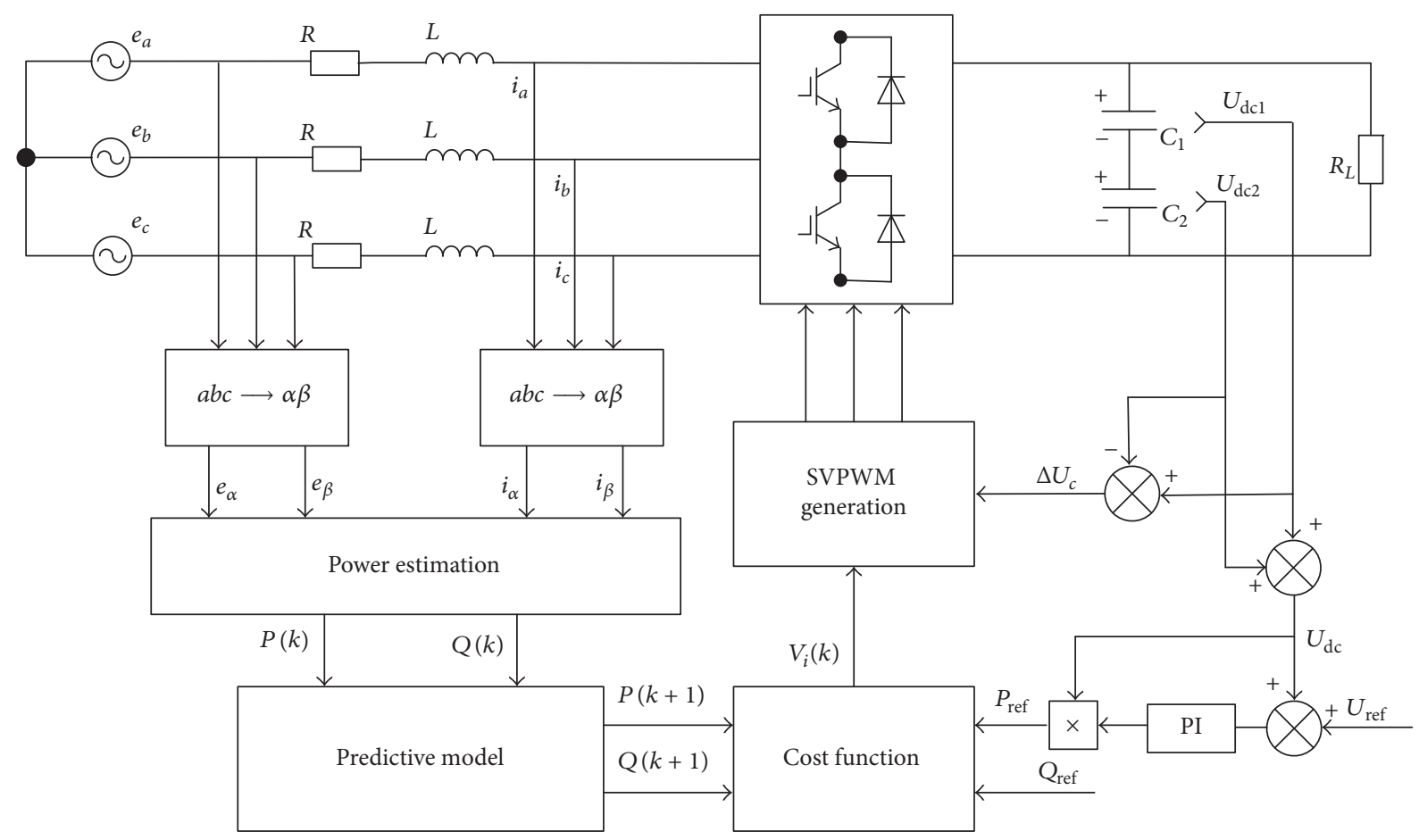

FIGURE 2: Block diagram of direct power control for three-level pulse rectifier model.

TABLE 1: Corresponding table of different voltage vectors and neutral point current.

\begin{tabular}{lc}
\hline Positive small vector & $i_{n}$ \\
\hline ppo & $i_{c}$ \\
opo & $-i_{b}$ \\
opp & $i_{a}$ \\
oop & $-i_{c}$ \\
pop & $i_{b}$ \\
poo & $-i_{a}$ \\
\hline Negative small vector & $i_{n}$ \\
\hline oon & $i_{c}$ \\
non & $i_{b}$ \\
noo & $-i_{a}$ \\
nno & $i_{c}$ \\
ono & $-i_{b}$ \\
onn & $i_{a}$ \\
\hline Neutral vector & $i_{n}$ \\
\hline opn & $i_{a}$ \\
npo & $i_{c}$ \\
nop & $i_{b}$ \\
onp & $i_{a}$ \\
pno & $i_{c}$ \\
pon & $i_{b}$ \\
\hline
\end{tabular}

The neutral point current of the negative small vector is defined as the balance current $i_{b l}$. From Figure 1, if the neutral point potential is connected with any one of the three-phase

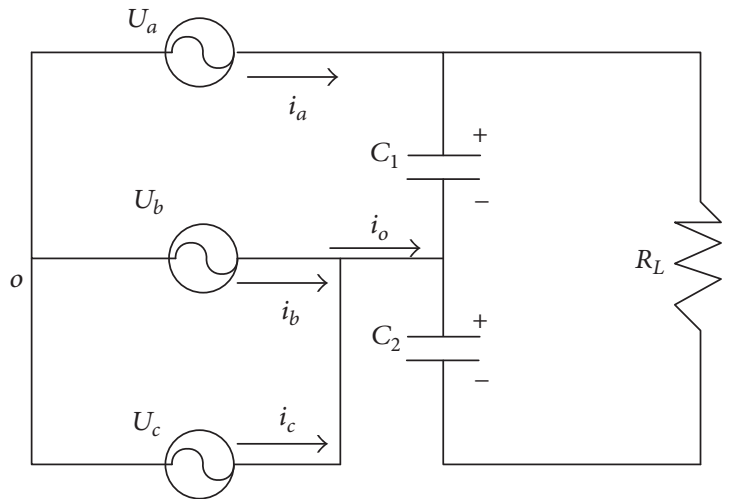

FIGURE 3: Switch state circuit diagram of the corresponding positive small vector.

network sides, then the output current of this phase is charged to the neutral point potential. Neutral point current can be obtained through the real time vector state, the switch status of each bridge $\operatorname{arm} S_{A}, S_{B}, S_{C}$ is, respectively, $1(p), 0(o),-1(n)$, a total of 27 kinds of switch state combination; among them, the action circuit diagram of the positive small vector poo and the negative small vector onn is as shown in Figures 3 and 4, respectively.

As shown in Figures 3 and 4, the formula of the midpoint current can be obtained:

$$
i_{o}=\delta\left(S_{A}\right) i_{a}+\delta\left(S_{B}\right) i_{b}+\delta\left(S_{C}\right) i_{c},
$$

where $S_{A}, S_{B}, S_{C} \in\{1,0,-1\}$ are three-phase bridge arm switch status and $\delta()$ is the impact function; when the switch 


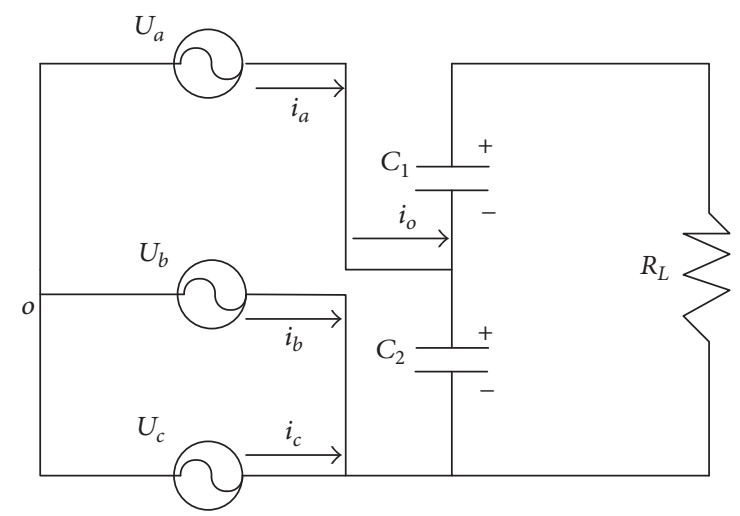

FIGURE 4: Switch state circuit diagram of the corresponding negative small vector.

status of each bridge $\operatorname{arm} S_{A}, S_{B}, S_{C}$ is $0, \delta(0)=1$; when the switch status is 1 or $-1, \delta(-1)=\delta(1)=0$.

In Figure 3, the switch status of each bridge $\operatorname{arm} S_{A}, S_{B}, S_{C}$ is $(1,0,0)$, corresponding positive small vector poo; formula (17) can be obtained:

$$
i_{o}=\delta(1) i_{a}+\delta(0) i_{b}+\delta(0) i_{c}=i_{b}+i_{c}=-i_{a} .
$$

In Figure 4, the switch status of each bridge arm $S_{A}, S_{B}$, $S_{C}$ is $(0,-1,-1)$, corresponding negative small vector onn; formula (18) can be obtained:

$$
i_{o}=\delta(0) i_{a}+\delta(-1) i_{b}+\delta(-1) i_{c}=i_{a}
$$

The midpoint current obtained from the current calculation formula as shown in (16) is in line with Figures 3 and 4 and Table 1.

Assume that each sampling period takes a negative small vector as the initial vector, the corresponding balance current of the initial negative small vector in any triangle region is $i_{b l}$, two capacitors' voltages of $\mathrm{DC}$ side are, respectively, $U_{\mathrm{dcl}}$, $U_{\mathrm{dc} 2}$; then the difference between the two capacitors' voltages is $\Delta U_{\mathrm{dc}}=U_{\mathrm{dc} 1}-U_{\mathrm{dc} 2}$.

In order to maintain neutral point voltage balance, if $\Delta U_{\mathrm{dc}}>0$, the voltage at both ends of the capacitor $C_{1}$ is reduced, and the voltage at both ends of the capacitor $C_{2}$ is increased. If $\Delta U_{\mathrm{dc}}<0$, the voltage at both ends of the capacitor $C_{1}$ is increased, and the voltage at both ends of the capacitor $C_{2}$ is reduced.

The relationship between the balance current and the two capacitors voltage is as follows.

When $i_{b l}>0$, negative small vectors will reduce the voltage on both ends of the capacitor $C_{1}$, while the corresponding positive small vector will reduce the voltage at both ends of the capacitor $C_{2}$. When $i_{b l}<0$, negative small vectors will increase the voltage on both ends of the capacitor $C_{1}$, while the corresponding positive small vector will increase the voltage at both ends of the capacitor $C_{2}$.

To sum up, the positive and negative relationship can get four combinations listed below, and the scheduling scheme of small vector time under different combinations is given.

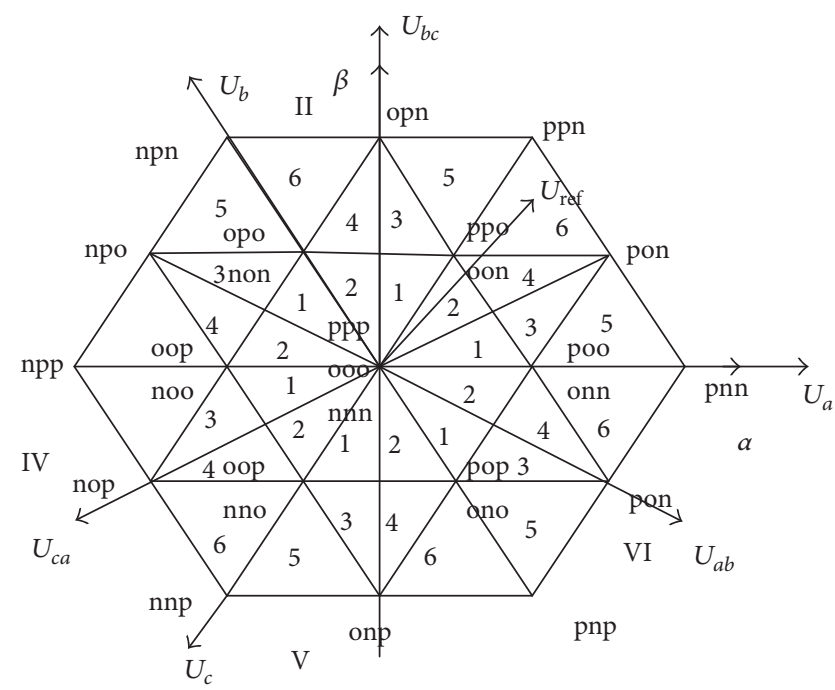

FIGURE 5: Space vector diagram of three-level rectifier.

(1) When $\Delta U_{\mathrm{dc}}>0, i_{b l}>0$, the negative small vector time should be reduced and the time of the positive small vector should be increased.

(2) When $\Delta U_{\mathrm{dc}}>0, i_{b l}<0$, the negative small vector time should be increased and the time of the positive small vector should be reduced.

(3) When $\Delta U_{\mathrm{dc}}<0, i_{b l}>0$, the negative small vector time should be reduced and the time of the positive small vector should be increased.

(4) When $\Delta U_{\mathrm{dc}}<0, i_{b l}<0$, the negative small vector time should be increased and the time of the positive small vector should be reduced.

Set adjustment factor as $k$ and the total time of positive and negative small vectors as $T_{a}$. The function time of positive and negative small vectors is assigned as follows.

The function time of negative small vectors is $T_{n}=$ $\left(T_{a} / 2\right)(1+k)$.

The function time of positive small vectors is $T_{p}=$ $\left(T_{a} / 2\right)(1-k)$.

(1) The Calculation Process of $k$. According to the above conclusions, the value adjustment factor $k$ is determined according to the following principles.

In the situation of (1) and (3), and $\left|\Delta U_{\mathrm{dc}}\right|>2, k=-0.5$. In the situation of (2) and (4), and $\left|\Delta U_{\mathrm{dc}}\right|>2, k=0.5$. In any other case, $\left|\Delta U_{\mathrm{dc}}\right|<2, k=0$.

(2) The Calculation Process of $T_{a}$. For rectifier modulation strategy, SVPWM modulation is adopted; the space vector region division is shown in Figure 5.

In SVPWM modulation, the vector state is sorted according to the central symmetric seven-section method. Take big district I and small district 1 as an example, the space vector diagram in this area is shown in Figure 6, and the corresponding relationship between state order of the basic vector and state actuation duration is shown in Figure 7. 


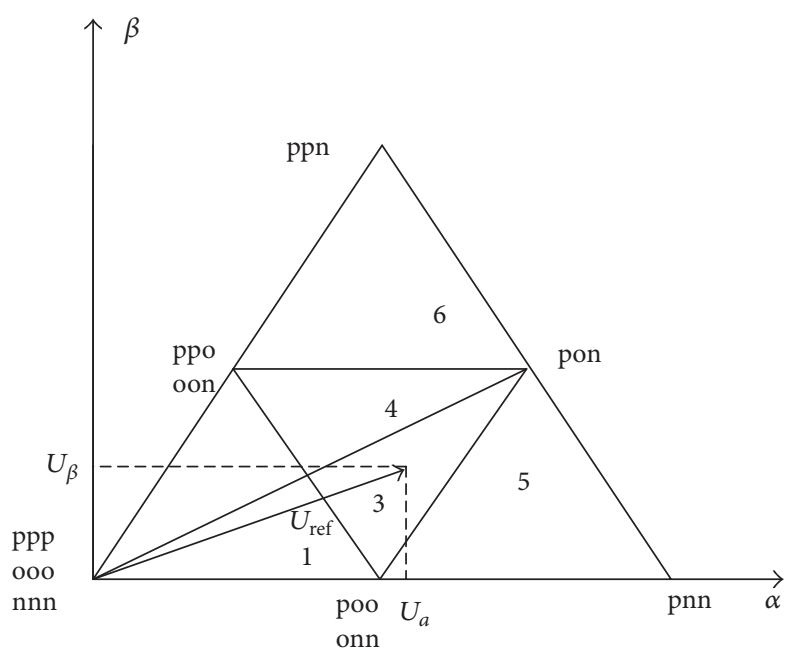

FIgURE 6: Space vector diagram of I big district.

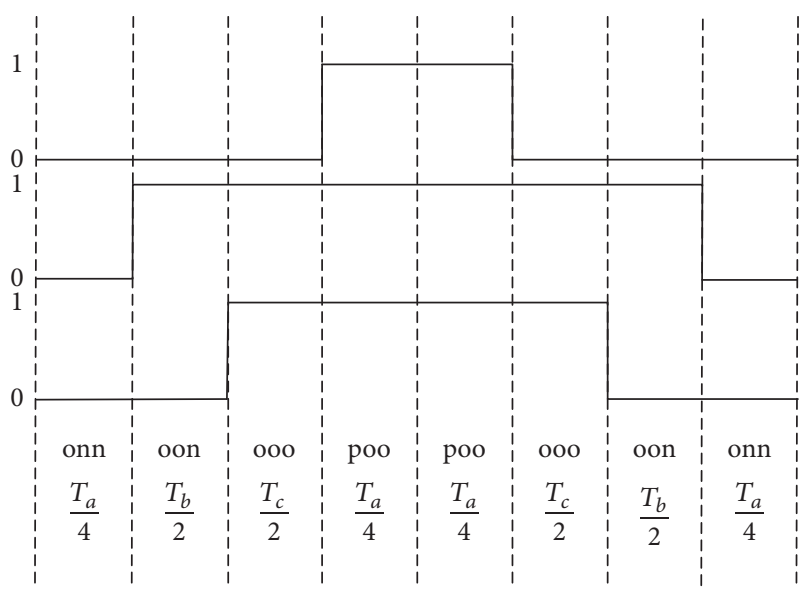

FIGURE 7: Seven-section SVPWM waveform (I1).

According to Figure 7, in district I1, the order of the basic space vectors is onn oon ooo poo ooo oon onn, the positive and negative vectors adopted are poo and onn, respectively, and the total actuation duration is set to $T_{a}$.

Take district I1, for example; the fundamental vector action time is calculated as follows.

Set $U_{o}=0$ to zero vector, the corresponding space vector state is ooo, $U_{1}=(1 / 2) U_{\mathrm{dc}}$ is small vector, the corresponding space vector state is poo and onn, $U_{2}=(1 / 2) U_{\mathrm{dc}} e^{j(\pi / 3)}$ is middle vector, and the corresponding space vector state is oon.

The second volt equilibrium equation is expressed as

$$
\begin{aligned}
U_{0} T_{c}+U_{1} T_{a}+U_{2} T_{b} & =U_{\mathrm{ref}} T_{s} e^{j(\pi / 3)}, \\
T_{a}+T_{b}+T_{c} & =T_{s} .
\end{aligned}
$$

TABLE 2: System parameters.

\begin{tabular}{lcc}
\hline Source voltage & $e$ & $600 \mathrm{~V}$ \\
Resistance & $R$ & $0.1 \Omega$ \\
Inductance & $L$ & $20 \mathrm{mH}$ \\
DC-link voltage & $U_{\mathrm{dc}}$ & $500 \mathrm{~V}$ \\
DC-link capacitor & $C_{1} / C_{2}$ & $7.5 \mathrm{mF}$ \\
Sampling period & $T_{s}$ & $50 \mathrm{us}$ \\
\hline
\end{tabular}

Substituting $U_{0}, U_{1}, U_{2}$ into formula (19), thus

$$
\begin{aligned}
& \frac{1}{2} U_{\mathrm{dc}} T_{a}+\frac{1}{2} U_{\mathrm{dc}}\left(\cos \frac{\pi}{3}+j \sin \frac{\pi}{3}\right) T_{b} \\
& =U_{\mathrm{ref}} T_{s}(\cos \theta+j \sin \theta), \\
& T_{a}+T_{b}+T_{c}=T_{s},
\end{aligned}
$$

where $U_{\text {ref }}$ is reference voltage.

Make the real part and imaginary part equal on both sides of the equation in formula (20); the actuation duration of each vector is as follows:

$$
\begin{aligned}
& T_{a}=2 m T_{s} \sin \left(\frac{\pi}{3}-\theta\right), \\
& T_{b}=2 m T_{s} \sin \theta, \\
& T_{c}=T_{s}-2 m T_{s} \sin \left(\frac{\pi}{3}+\theta\right) .
\end{aligned}
$$

In the formula

$$
m=\frac{2 U_{\mathrm{ref}}}{\sqrt{3} U_{\mathrm{dc}}} .
$$

In formula (21), $T_{a}$ is the total actuation duration of positive and negative small vectors in a cycle, $T_{b}$ is the total actuation duration of middle vector, and $T_{c}$ is the total actuation duration of zero vector.

Assign basic actuation duration to the corresponding vector states; that is, assign the switching device turn-on or turn-off time to the corresponding switching device, to complete the control of the main circuit to the switching device.

\section{Results of Experiment and Simulation}

4.1. Simulation Results. In order to verify the correctness of the proposed two-step predictive control method and the neutral point potential balance control method, the traditional direct power control, one-step predictive control, and two-step predictive control are carried out through the Simulink simulation. Three-level pulse rectifier Simulink simulation parameters are shown in Table 2.

The system is suddenly added the load at $0.3 \mathrm{~s}$. Figures 8 and 11 show the traditional direct power control simulation results. Figures 9 and 12 show one-step predictive control simulation. Figures 10 and 13 show the two-step predictive control simulation. Figures 14 and 15, respectively, show the two capacitors' voltage of DC side; Figure 14 is the result 

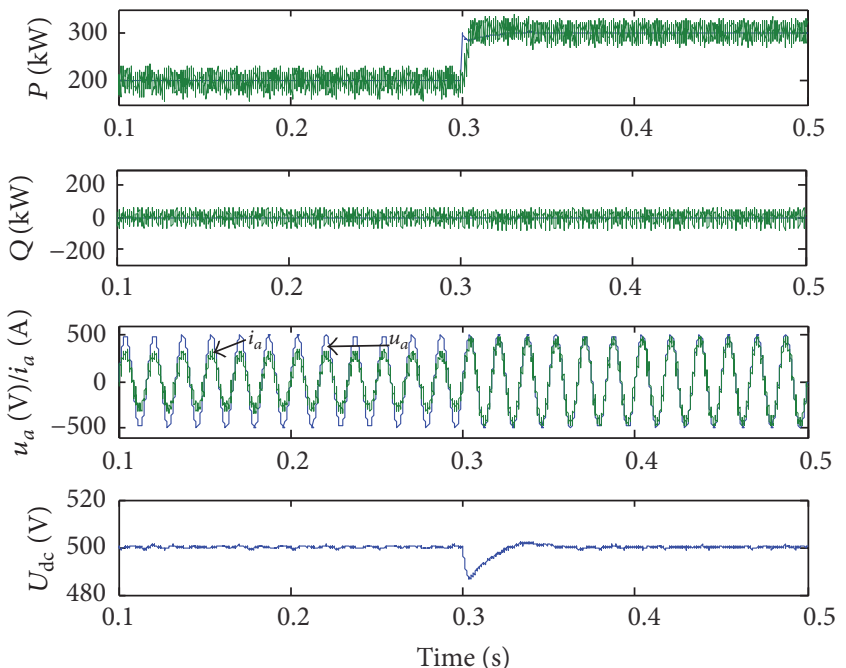

FIgURE 8: Traditional direct power control simulation.
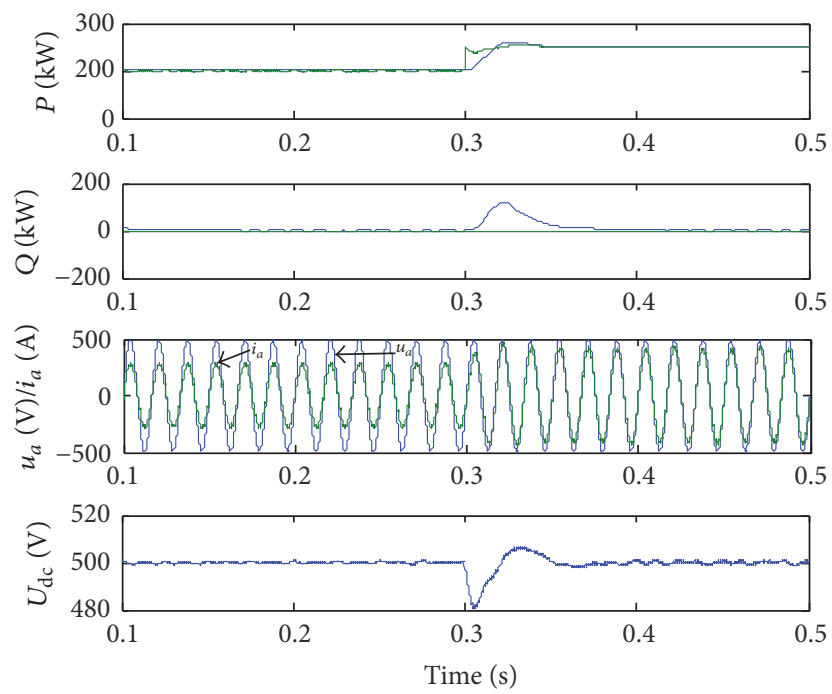

Figure 9: One-step predictive control simulation.
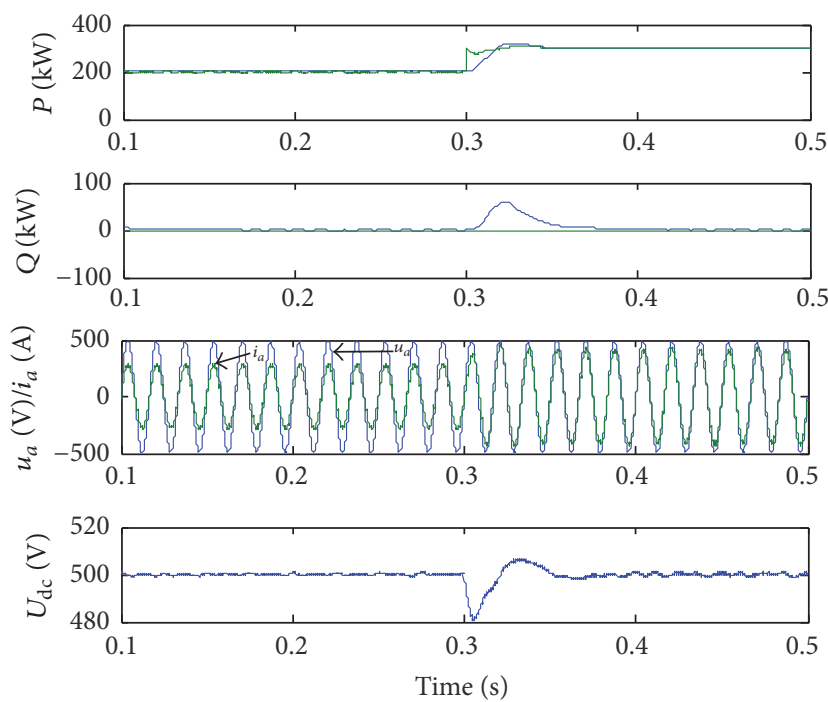

Figure 10: Two-step predictive control simulation.

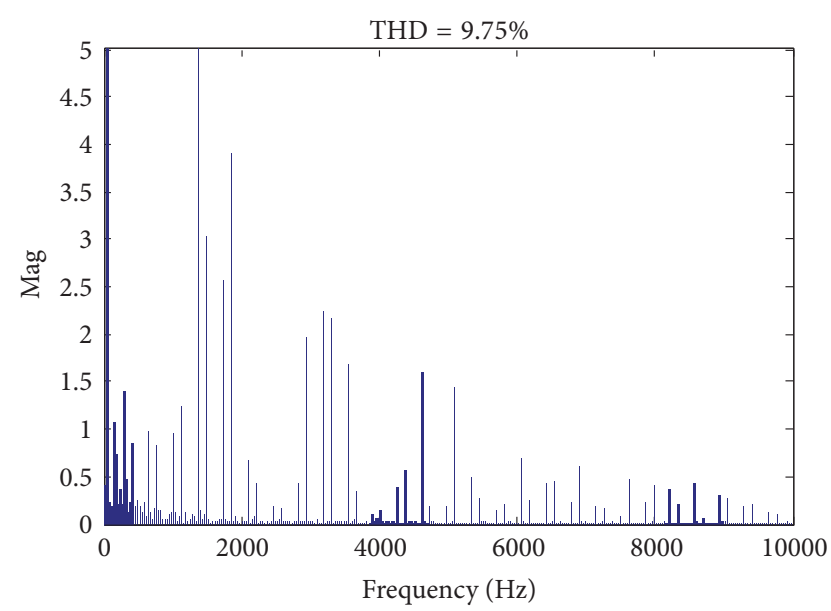

FIGURE 11: Traditional direct power control current spectrum analysis.

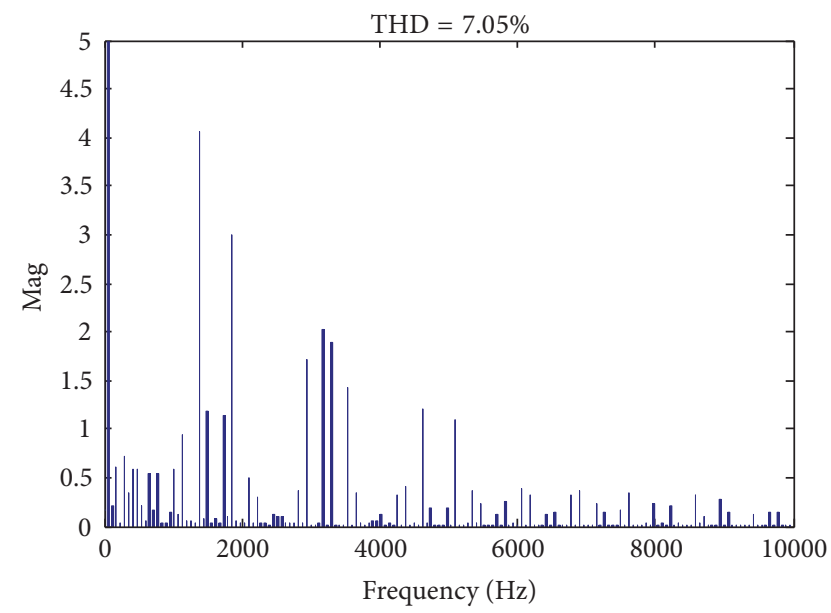

FIGURE 12: One-step predictive control current spectrum analysis.

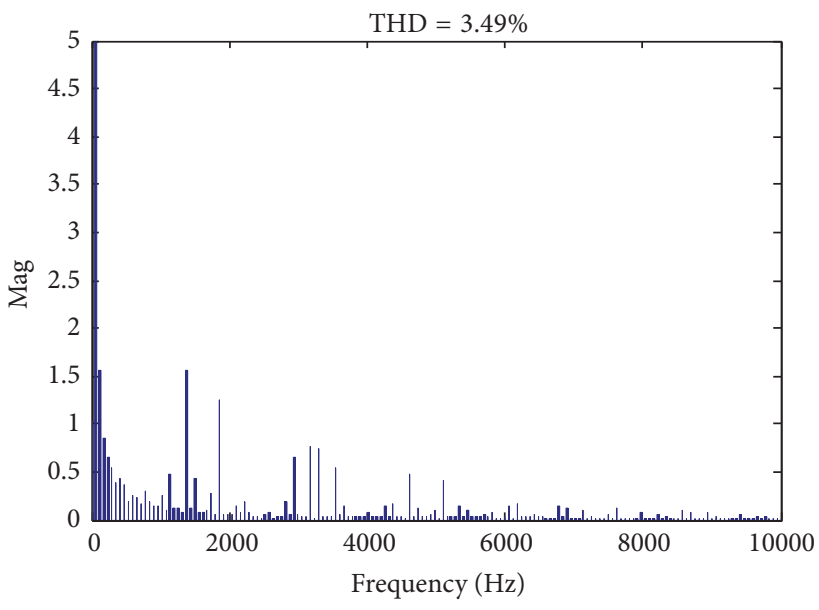

FIGURE 13: Two-step predictive control current spectrum analysis. 


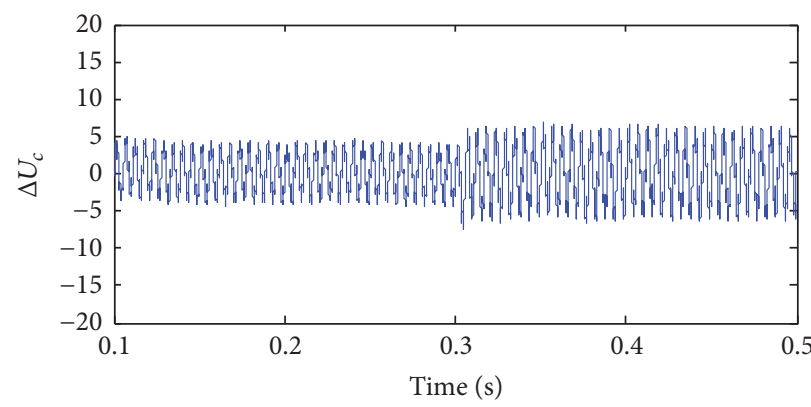

FIGURE 14: $\Delta U_{\mathrm{dc}}$ of two-step predictive control DC.

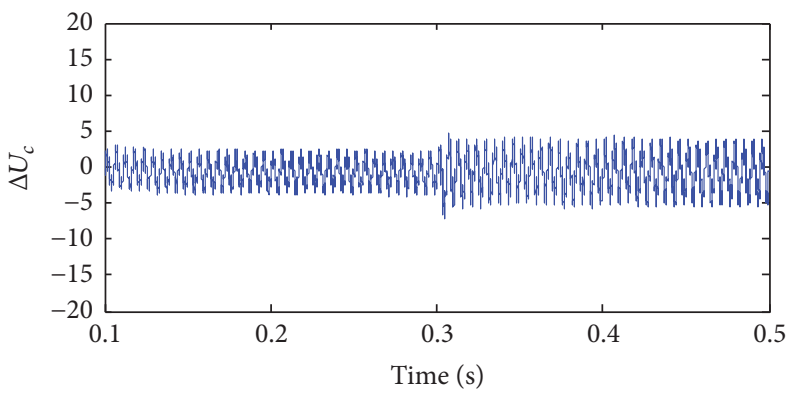

FIGURE 15: $\Delta U_{\mathrm{dc}}$ of two-step predictive control DC after adding neutral point potential control.

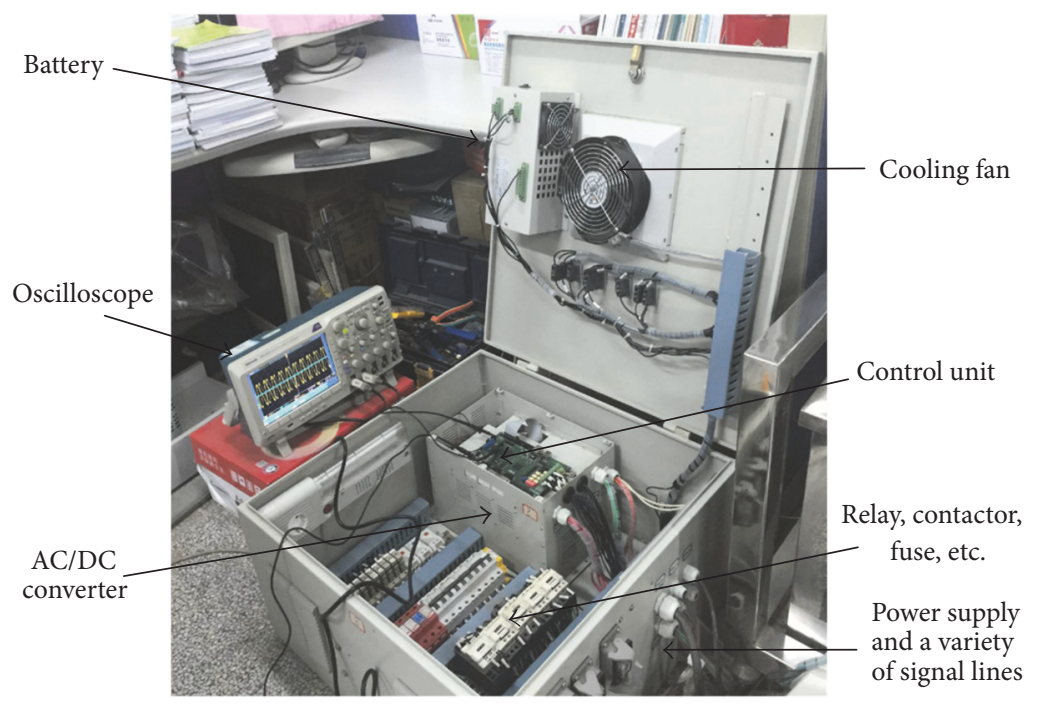

Figure 16: Laboratory test bench.

of the two-step predictive control and Figure 15 adds twostep predictive control and neutral voltage control. It can be seen that, after adding neutral voltage control to the system, the problem of the capacitor voltage imbalance is improved obviously.

From Figures 8, 10, and 13, we can see that TMPDPC control effect is the best, the accuracy is the highest, and the lag time is the shortest. THD of DPC is $9.75 \%$, THD of OMPDPC is $7.05 \%$, and THD of TMPDPC is $3.49 \%$.
From Figures 14 and 15, we can see that, after adding the midpoint potential method, the DC side two-capacitor voltage deviation is obviously reduced.

4.2. Experiment Results. The proposed predictive direct power control strategy was tested experimentally using a laboratory AC/DC converter system, as shown in Figure 16. A TMS320F2812 DSP was used for the control. The converter input active and reactive power are displayed through digital 

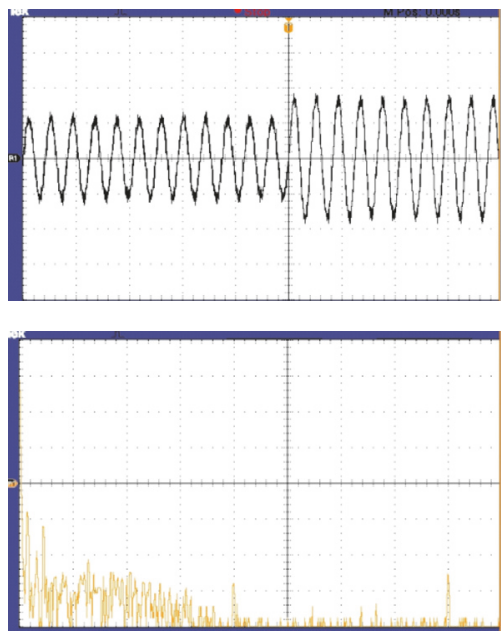

(a) Experimental result of traditional DPC
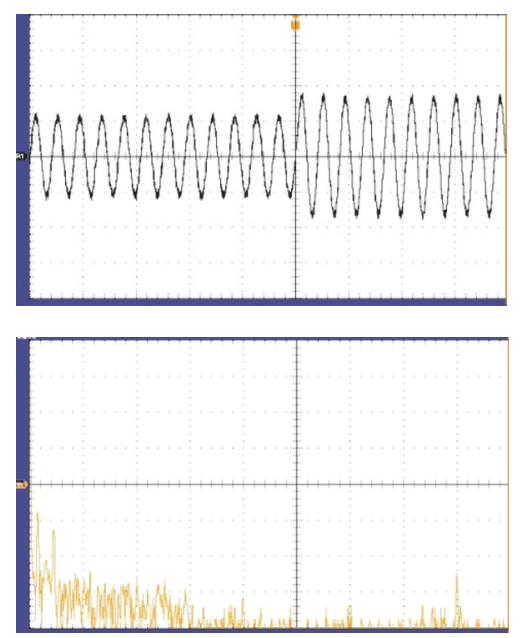

(b) Experimental result of one-step predictive control
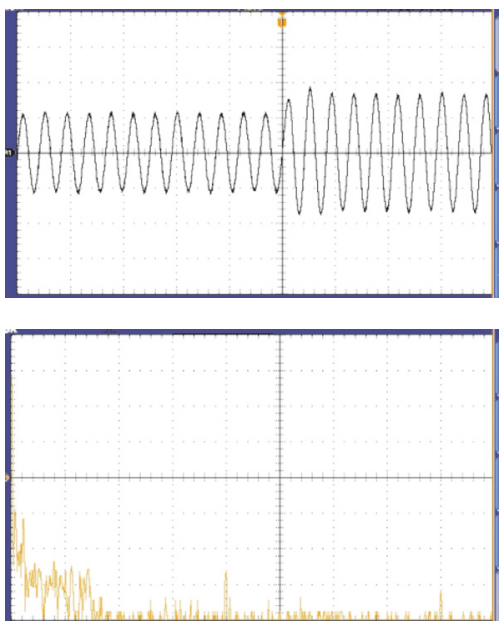

(c) Experimental result of two-step predictive control

FIgURE 17: Experimental results comparison of three methods.

to analog conversion (DAC) ranged from 0 to $5 \mathrm{~V}$ with $2.5 \mathrm{~V}$ corresponding to $0 \mathrm{~W}(\mathrm{~V} \mathrm{Ar})$. The oscilloscope uses the double trace channel.

For the same conditions as the simulation study, Figure 17 compares the experimental results of traditional DPC OMPDPC and TMPDPC; the waveform of single phase current and FFT are obtained by experiments.

It can be seen that the experimental results are in good agreement with the simulation (from Figures 8 and 10). Experimental results of TMPDPC are the best; it produces less power ripple and a more stable DC-link. voltage. Overall, better performance in terms of line current THD and active and reactive power ripple are achieved using TMPDPC, compared with DPC, and OMTDPC delay compensation further improves the performance.

\section{Conclusion}

In this paper, DPC, OMPDPC, and TMPDPC combined with the neutral point potential method are used to make the control simulation analysis of the rectifier. The method proposed in this paper not only solves the problem that the traditional direct power control switch frequency is not fixed (the system is delayed) but also solves the neutral point potential unbalance problem of the three-level rectifier, which can obtain good dynamic and steady state performance and make the system DC power supply more stable.

\section{Conflicts of Interest}

The authors declare that they have no conflicts of interest.

\section{Acknowledgments}

This work is partially supported by the National Fund of China (no. 51667013).

\section{References}

[1] Q. Cheng, C. Xu, Y. Cheng, W. Huang, and K. Guo, "Coordination control of PV charging station DC microgrid system based on hybrid energy storage technology," High Voltage Engineering, vol. 42, no. 7, pp. 2073-2083, 2016.

[2] Y.-C. Zhang and W. Xie, "Direct mean power control of PWM rectifier," Automation of Electric Power Systems, vol. 38, no. 5, pp. 90-95, 2014.

[3] Y. Zhang, Z. Li, Y. Zhang et al., "Performance improvement of direct power control of PWM rectifier with simple calculation," IEEE Transactions on Power Electronics, vol. 28, no. 7, pp. 34283437, 2013.

[4] Y. Zhang, W. Xie, Z.-X. Li et al., "Model predictive direct power control of a PWM rectifier with duty cycle optimization," IEEE Transactions on Power Electronics, vol. 28, no. 11, pp. 5343-5351, 2013.

[5] L. Derong, J. Xiaohao, H. Sheng et al., "Model predictive direct power control for three-phase voltage source PWM rectifiers," Power System Technology, vol. 38, no. 11, pp. 3109-3114, 2014.

[6] R. Portillo, S. Vazquez, J. I. Leon, M. M. Prats, and L. G. Franquelo, "Model based adaptive direct power control for three-level NPC converters," IEEE Transactions on Industrial Informatics, vol. 9, no. 2, pp. 1148-1157, 2012.

[7] D.-K. Choi and K.-B. Lee, "Dynamic performance improvement of $\mathrm{AC} / \mathrm{DC}$ converter using model predictive direct power control with finite control set," IEEE Transactions on Industrial Electronics, vol. 62, no. 2, pp. 757-767, 2015.

[8] M. Preindl, E. Schaltz, and P. Thogersen, "Switching frequency reduction using model predictive direct current control for high-power voltage source inverters," IEEE Transactions on Industrial Electronics, vol. 58, no. 7, pp. 2826-2835, 2011.

[9] P. Karamanakos, T. Geyer, N. Oikonomou, F. D. Kieferndorf, and S. Manias, "Direct model predictive control: A review of strategies that achieve long prediction intervals for power electronics," IEEE Industrial Electronics Magazine, vol. 8, no. 1, pp. 32-43, 2014.

[10] A. J. Sguarezi Filho and E. R. Filho, "Model-based predictive control applied to the doubly-fed induction generator direct 
power control," IEEE Transactions on Sustainable Energy, vol. 3, no. 3, pp. 398-406, 2012.

[11] M. Moazen, R. Kazemzadeh, and M.-R. Azizian, "Modelbased predictive direct power control of brushless doubly fed reluctance generator for wind power applications," Alexandria Engineering Journal, vol. 55, no. 3, pp. 2497-2507, 2016.

[12] V. Spudić, C. Conte, M. Baotić, and M. Morari, "Cooperative distributed model predictive control for wind farms," Optimal Control Applications and Methods, vol. 36, no. 3, pp. 333-352, 2015.

[13] J. Hu, J. Zhu, G. Platt, and D. G. Dorrell, "Model-predictive direct power control of AC/DC converters with one step delay compensation," in Proceedings of the 38th Annual Conference of IEEE Industrial Electronics (IECON '12), pp. 4892-4897, Montreal, QC, Canada, October 2012.

[14] W.-X. Yao, Z.-Y. Lü, W.-M. Fei, and Z.-M. Qian, "A new three-level neutral point potential hysteresis-band control," in Proceedings of the CSEE, vol. 25, pp. 92-96, Chinese Society of Electrical Engineering, April 2005.

[15] Z. Shu, N. Ding, J. Chen, H. Zhu, and X. He, "Multilevel SVPWM with DC-link capacitor voltage balancing control for diode-clamped multilevel converter based STATCOM," IEEE Transactions on Industrial Electronics, vol. 60, no. 5, pp. 18841896, 2013.

[16] M. Saeedifard, H. Nikkhajoei, R. Iravani, and A. Bakhshai, Space vector modulation approach for a multi-module HVDC converter system, University of Toronto, Toronto, Canada, 2008, Ph.D Dissertation Electrical And Computer Engineering.

[17] W.-B. Song, H. Wang, X. Zhang, M.-L. Zhang, and L.-H. Qu, "Improved predictive direct power control of three phase pwm rectifier," Control Engineering of China, vol. 23, no. 2, pp. 227232, 2016.

[18] L. Bin, H. Kailun, W. Jiaju, and L. Jun, "A novel SVPWM method considering neutral-point potential balancing and reducing switching losses for three-level inverter," Transactions of China Electrotechnical Society, vol. 30, no. 4, pp. 196-202, 2015. 


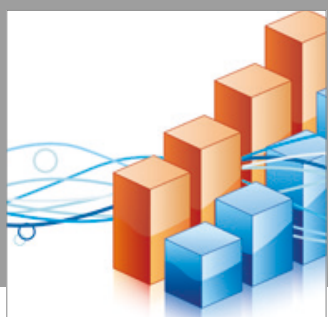

Advances in

Operations Research

vatersals

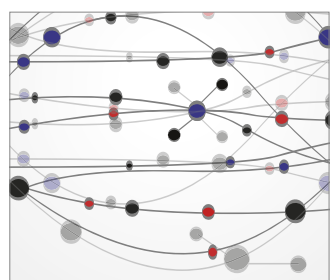

\section{The Scientific} World Journal
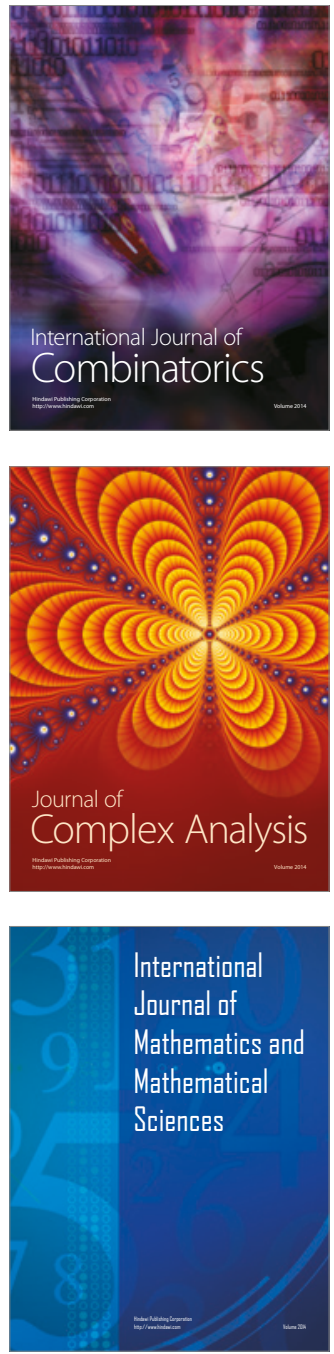
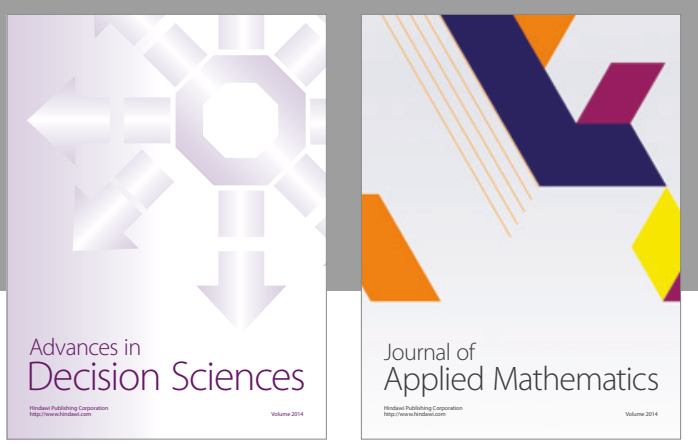

Algebra

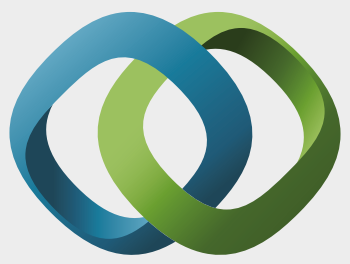

\section{Hindawi}

Submit your manuscripts at

https://www.hindawi.com
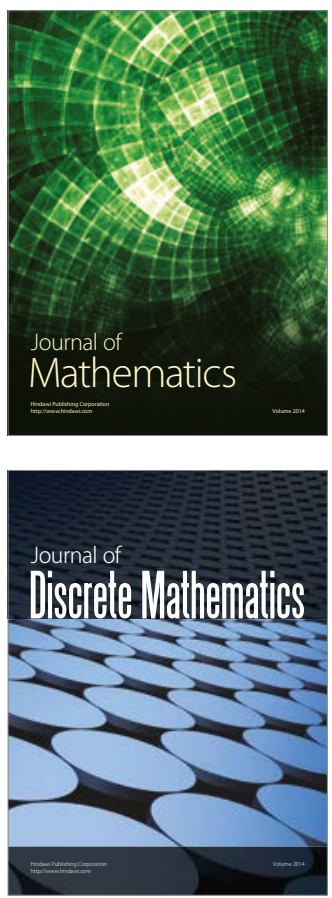

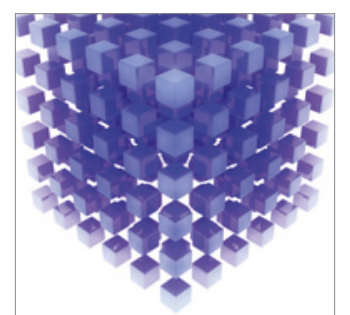

Mathematical Problems in Engineering
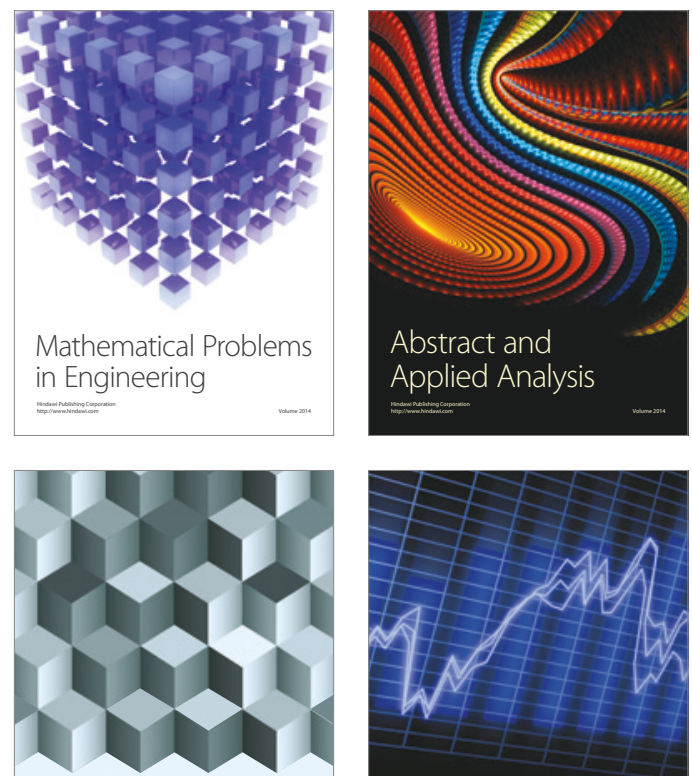

Journal of

Function Spaces

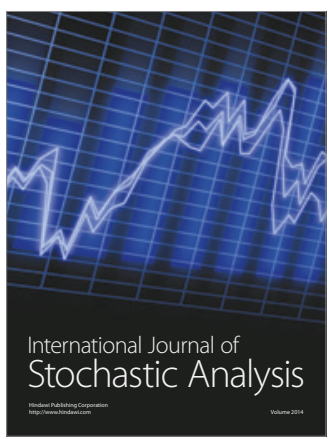

Probability and Statistics
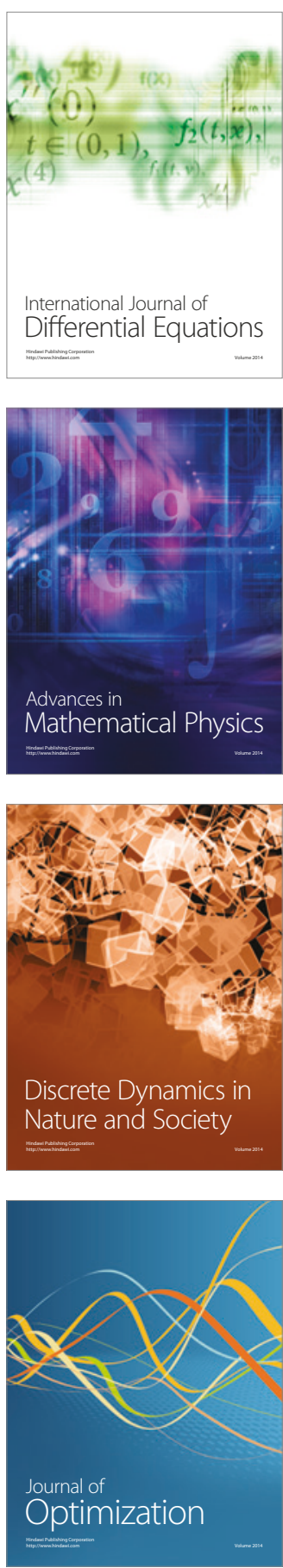